\title{
Utility of oxygen insufflation through working channel during fiberoptic intubation in apneic patients: a prospective randomized controlled study
}

\author{
Go Un Roh ${ }^{1}$, Joon Gwon Kang ${ }^{1}$, Jung Youn $\mathrm{Han}^{1}$ and Chul Ho Chang ${ }^{2^{*}}$
}

\begin{abstract}
Background: Airway management is a part of routine anesthetic procedures; however, serious complications, including hypoxia and death, are known to occur in cases of difficult airways. Therefore, alternative techniques such as fiberoptic bronchoscope-assisted intubation (FOB intubation) should be considered, although this method requires more time and offers a limited visual field than does intubation with a direct laryngoscope. Oxygen insufflation through the working channel during FOB intubation could minimize the risk of desaturation and improve the visual field. Therefore, the aim of this prospective randomized controlled study was to evaluate the utility and safety of oxygen insufflation through the working channel during FOB intubation in apneic patients.

Methods: Thirty-six patients were randomly allocated to an $\mathrm{N}$ group (no oxygen insufflation) or an $\mathrm{O}$ group (oxygen insufflation). After preoxygenation, FOB intubation was performed with (O group) or without ( $\mathrm{N}$ group) oxygen insufflation in apneic patients. The primary outcome was the velocity of decrease in the partial pressure of oxygen $\left(\mathrm{PaO}_{2}\right)$ during $\mathrm{FOB}$ intubation $\left(\mathrm{V}_{\mathrm{PaO}}, \mathrm{mmHg} / \mathrm{sec}\right)$ defined as the difference of $\mathrm{PaO}_{2}$ before and after intubation divided by the time to intubation. The secondary outcomes included the success rate for FOB intubation, time to intubation, visual field during FOB intubation, findings of arterial blood gas analysis, and occurrence of FOB intubation-related complications.
\end{abstract}

Results: We found that $\mathrm{V}_{\mathrm{PaO} 2}$ was significantly greater in the $\mathrm{N}$ group than in the $\mathrm{O}$ group $(1.0 \pm 0.4 \mathrm{vs}$. $0.4 \pm 0.4$; $p<0.001$ ), while the visual field was similar between groups. There were no significant intergroup differences in the secondary outcomes.

Conclusions: These findings suggest that oxygen insufflation through the working channel during FOB intubation aids in extending the apneic window during the procedure.

Trial registration: ClinicalTrials.gov, NCT02625194, registered at December 9, 2015.

Keywords: Fiberoptic intubation, Apneic oxygenation, Oxygenation during intubation

\footnotetext{
* Correspondence: anezzang@yuhs.ac

${ }^{2}$ Department of Anesthesiology and Pain Medicine, and Anesthesia and Pain

Research Institute, Yonsei University College of Medicine, Gangnam

Severance Hospital, 211 Eonju-ro, Gangnam-gu, Seoul 06273, Korea

Full list of author information is available at the end of the article
}

(c) The Author(s). 2020 Open Access This article is licensed under a Creative Commons Attribution 4.0 International License, which permits use, sharing, adaptation, distribution and reproduction in any medium or format, as long as you give appropriate credit to the original author(s) and the source, provide a link to the Creative Commons licence, and indicate if changes were made. The images or other third party material in this article are included in the article's Creative Commons licence, unless indicated otherwise in a credit line to the material. If material is not included in the article's Creative Commons licence and your intended use is not permitted by statutory regulation or exceeds the permitted use, you will need to obtain permission directly from the copyright holder. To view a copy of this licence, visit http://creativecommons.org/licenses/by/4.0/ The Creative Commons Public Domain Dedication waiver (http://creativecommons.org/publicdomain/zero/1.0/) applies to the data made available in this article, unless otherwise stated in a credit line to the data. 


\section{Background}

Airway management is a part of essential anesthetic procedures. However, it becomes challenging in cases of difficult airways and may cause several complications, including airway trauma, hypoxia, and even death $[1,2]$. Therefore, intubation techniques involving the use of fiberoptic bronchoscopes (FOBs) and videolaryngoscopes should be considered as alternative options [3, 4]. During FOB-assisted intubation (FOB intubation), superior visualization of anatomical structures is the key for successful intubation, and suction through the working channel of FOB is commonly performed for the clearance of secretions and blood and improvement of the visual field. Oxygen insufflation through this working channel during the procedure is also possible and recommended by some physicians [5-7]. Oxygen insufflation through the working channel during FOB intubation, which requires a longer time than does direct laryngoscopic intubation, can minimize the risk of desaturation in apneic patients [8]. In addition, oxygen flow at the end of FOB could help in the clearance of secretions and small structural barriers, resulting in improved visualization during the procedure $[5,9]$. However, a few reports have documented rare but critical complications such as gastric rupture and pneumothorax [10-12]. Moreover, this technique is not recommended for pediatric patients or patients with significant airway edema [11]. Thus, oxygen insufflation through the working channel during FOB intubation has certain advantages and limitations. However, few studies have evaluated its utility and safety in clinical practice. Therefore, the aim of the present study was to evaluate the utility and safety of oxygen insufflation through the working channel during FOB intubation via measurement of the velocity of decrease in the partial pressure of oxygen $\left(\mathrm{PaO}_{2}\right)$ during the procedure $\left(\mathrm{V}_{\mathrm{PaO} 2}\right)$. In addition, the time to intubation, visual field, and occurrence of $\mathrm{FOB}$ intubation-related complications were investigated.

\section{Methods}

\section{Patients}

This prospective randomized controlled study was approved by the Institutional Review Board of Yonsei University Gangnam Severance Hospital (IRB No 3-20150218, NCT02625194, https:/clinicaltrials.gov/ct2/show/ NCT02625194?term=NCT02625194\&rank=1). After the acquisition of written informed consent, 36 patients aged 20-60 years (American Society of Anesthesiolgists class I to III) who were scheduled for elective surgery under general endotracheal anesthesia with arterial cannulation at Yonsei University Gangnam Severance Hospital were included. The exclusion criteria included lung disease, anticipated difficult airway, inability to read or write, and pregnancy. The randomization table at www.random.org was used to allocate patients to an $\mathrm{N}$ group (no oxygen insufflation) or an $\mathrm{O}$ group (oxygen insufflation) at ratio of $1: 1$.

\section{Study design and procedure}

After premedication with $0.02 \mathrm{mg} / \mathrm{kg}$ of midazolam and $0.004 \mathrm{mg} / \mathrm{kg}$ of glycopyrrolate in the preanesthesia care unit, patients were transferred to the operating room, where standard monitoring procedures, including electrocardiography, pulse oximetry, and noninvasive blood pressure measurement, were initiated. Vital signs, including the heart rate, systolic blood pressure, diastolic blood pressure, and peripheral oxygen saturation, were recorded before anesthesia induction. Preoxygenation with $100 \%$ oxygen using a facemask was performed for $5 \mathrm{~min}$, following which anesthesia was induced with propofol $1.5 \mathrm{mg} / \mathrm{kg}$, remifentanil $0.1 \mathrm{mcg} / \mathrm{kg} / \mathrm{min}$, and rocuronium $0.8 \mathrm{mg} / \mathrm{kg}$. The radial artery was cannulated during manual ventilation. After 2 min of manual ventilation, arterial blood was collected and the facemask was removed for intubation (T1). The airway was opened by the jaw thrust maneuver, and endotracheal intubation was performed using a flexible FOB (Intubation fiberscope, $5.2 \times 65 \mathrm{~mm}$, Karl Stortz GmbH \& CO, Germany) with a preloaded endotracheal tube. In the $\mathrm{O}$ group, $100 \%$ oxygen was administered at $5 \mathrm{~L} / \mathrm{min}$ through the working channel. The $\mathrm{N}$ group did not receive oxygen insufflation. Intubation success was confirmed by bronchoscopy, following which arterial blood was collected before the initiation of ventilation (T2). The first endtidal carbon dioxide value after the resumption of ventilation following intubation was recorded.

\section{Study endpoints}

The primary endpoint was $\mathrm{V}_{\mathrm{PaO} 2}$, defined as the difference of $\mathrm{PaO}_{2}$ between $\mathrm{T} 1$ and $\mathrm{T} 2$ divided by the time to intubation $(\mathrm{mmHg} / \mathrm{sec})$. Secondary endpoints included the FOB intubation success rate, time to intubation (from facemask removal until resumption of ventilation), visual field during FOB intubation (excellent, clear view of anatomical structures and no limitation; good, $<50 \%$ limitation in the view but no difficulty in intubation; poor, $>50 \%$ limitation in the view, resulting in significant difficulty in intubation; and impossible, inability to identify the anatomical structures and intubate), and occurrence of FOB intubation-related complications, including mucosal injury, abdominal distension, postoperative nausea and/or vomiting, and desaturation [peripheral capillary oxygen saturation $\left(\mathrm{SpO}_{2}\right)<90 \%$ ]. In addition, vital signs and $\mathrm{pH}$, partial pressure of carbon dioxide $\left(\mathrm{PaCO}_{2}\right)$, and $\mathrm{PaO}_{2}$ values were recorded for all patients. 


\section{Statistical analysis}

Considering the findings of Rosenstock, who reported a mean $\mathrm{V}_{\mathrm{PaO} 2}$ of $0.9 \mathrm{mmHg} / \mathrm{s}$ with a standard deviation of 0.17 , we found that 16 patients per group were required for detection of a $0.25 \mathrm{mmHg} / \mathrm{s}$ decrease in $\mathrm{V}_{\mathrm{PaO} 2}$ with a type 1 error and power of 0.05 and 80\%, respectively [13]. Accordingly, a total of 18 patients per group were included after accounting for the withdrawal rate during study. All statistical analyses were performed using SPSS, version 18.0 (SPSS Inc., Chicago, IL, USA). For $\mathrm{V}_{\mathrm{PaO} 2}$, Mann-Whitney U test was performed. Secondary endpoints including time to intubation, vital signs and arterial blood gas analysis data were also assessed with Mann-Whitney U test. Visual field and FOB intubationrelated complications were analysed by Fisher's exact test. In comparing the patients' characteristics, continuous variables were assessed using Mann-Whitney Utest, while categorical variables were assessed using the chi-square test or Fisher's exact test. The results from Mann-Whitney $U$ test were expressed as mean with standard deviation. The categorical data was presented as number. The Bonferroni method was used to compensate the error of multiple comparisons. A $P$-value of $<0.05$ was considered statistically significant.

\section{Results}

In total, 36 patients were enrolled, 35 of whom completed the study. One patient in the $\mathrm{N}$ group was excluded because of malfunction of the arterial blood gas analysis machine (Fig. 1). The patients' baseline characteristics were not different between the two groups (Table 1). All patients were successfully intubated. Vital signs and $\mathrm{pH}, \mathrm{PaCO}_{2}, \mathrm{PaO}_{2}$ and $\mathrm{SaO}_{2}$ values also showed no significant intergroup differences throughout the procedure. The time to intubation was approximately $150 \mathrm{~s}$ in both groups. Although $\mathrm{PaO}_{2}$ showed no significant intergroup differences at $\mathrm{T} 1$ and $\mathrm{T} 2$, the decrease in $\mathrm{PaO}_{2}$ during FOB intubation was significantly greater in the $\mathrm{N}$ group than in the $\mathrm{O}$ group $(139.4 \pm 74.3$ vs. $72.0 \pm$ 67.7, $p=0.012$ ). In addition, $\mathrm{V}_{\mathrm{PaO} 2}$ was significantly greater in the $\mathrm{N}$ group than in the $\mathrm{O}$ group $(1.0 \pm 0.4$ vs. $0.4 \pm 0.4, p<0.001)$. An excellent visual field was obtained for 12 and 7 patients in the $\mathrm{O}$ and $\mathrm{N}$ groups, respectively, with no significant intergroup difference. None of the patients presented mucosal injury, abdominal distension, and desaturation. One patient in the $\mathrm{O}$ group exhibited postoperative nausea (Table 2).

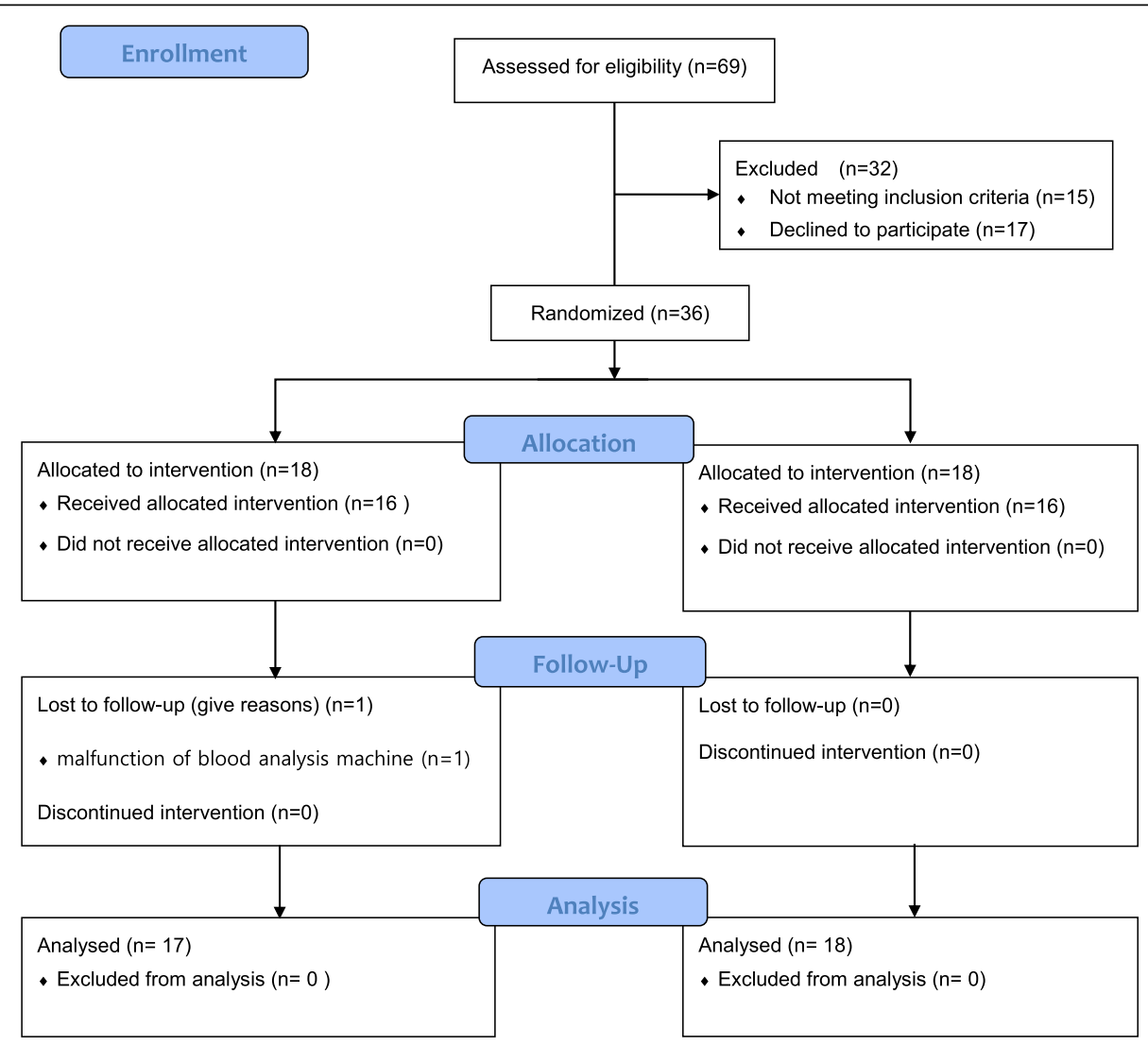

Fig. 1 CONSORT diagram showing the flow of participants 
Table 1 Patients' Characteristics

\begin{tabular}{lllll}
\hline & No Oxygen $(\boldsymbol{n}=\mathbf{1 7})$ & Oxygen $(\boldsymbol{n}=\mathbf{1 8})$ & $\boldsymbol{P}$-value & Standardized differences \\
\hline Age (year) & $53.1 \pm 15.7$ & $59.1 \pm 9.6$ & 0.330 & 0.622 \\
Sex (male, number) & $5(29.4 \%)$ & $6(33.3 \%)$ & 0.803 & 0.083 \\
Height (cm) & $161.6 \pm 10.7$ & $162.4 \pm 9.1$ & 0.655 & 0.094 \\
Weight (kg) & $63.9 \pm 12.5$ & $66.1 \pm 14.0$ & 0.741 & 0.159 \\
ASA Class & & & 0.391 & 0.581 \\
$\quad$ I & $8(47.1)$ & $4(22.2)$ & & \\
II & $8(47.1)$ & $12(66.7)$ & & \\
\hline III & $1(5.9)$ & $2(11.1)$ & & \\
\hline
\end{tabular}

Values are expressed as mean \pm standard deviation or number

ASA American Society of Anesthesiologist

\section{Discussion}

In the present study assessing the utility of oxygen insufflation during $\mathrm{FOB}$ intubation, $\mathrm{V}_{\mathrm{PaO} 2}$ was significantly reduced when oxygen was insufflated through the working channel. However, patients with and without oxygen insufflation showed no significant differences in the intubation success rate, time to intubation, visual field, and occurrence of complications.

Despite recent advances in airway management devices such as videolaryngoscopes and supraglottic airways, FOB intubation is still considered the gold standard for difficult airway management $[14,15]$. However, it requires a longer time than does intubation with a direct laryngoscope. In addition, secretions and bleeding in the airway obscure the airway anatomy and complicate intubation [3]. Therefore, methods to improve patient oxygenation after the induction of anesthesia can facilitate faster and safer FOB intubation.

Several studies have attempted to overcome the limitations of FOB intubation. A direct laryngoscope or GlideScope can assist the placement of FOB near the glottis and facilitate easy intubation [16-18]. In addition, supraglottic airways such as I-gel or LMA can be used as conduits for FOB intubation, providing a better route to the glottic inlet and, at the same time, ventilating the lungs during the procedure $[19,20]$. However, these techniques require the use of additional devices and result in an increased time to intubation. Especially, they are inappropriate in patients with limited mouth opening [21]. Oxygen insufflation through the working channel during FOB intubation does not require extra time and devices. Oxygen insufflation through the working channel of FOB could alleviate both hypoxia and visual field impairment in children [5]. In our study, $\mathrm{V}_{\mathrm{PaO} 2}$ was $1.01 \pm 0.39$ $\mathrm{mmHg} / \mathrm{s}$ in the $\mathrm{N}$ group, which was more than twice the value for the $\mathrm{O}$ group $(0.42 \pm 0.42 \mathrm{mmHg} / \mathrm{s})$. If the hypoxia-free apnea time during FOB intubation is defined as the time from the discontinuation of mask ventilation at a $\mathrm{PaO}_{2}$ of $500 \mathrm{mmHg}$ to the achievement of $90 \% \mathrm{SpO}_{2}$ at a $\mathrm{PaO}_{2}$ of $60 \mathrm{mmHg}$, under the assumption that $\mathrm{PaO}_{2}$ exhibits a linear decrease during apnea, the hypoxia-free apnea duration could be approximately 10 min longer in the $\mathrm{O}$ group than in the $\mathrm{N}$ group (1047.62 s vs. 435.64 s, respectively).

This calculation is based on a ventilatory mass flow, also known as apneic oxygenation. During regular breathing in an adult, oxygen and carbon dioxide are exchanged between the lungs and blood at a flow rate of $250 \mathrm{ml} / \mathrm{min}$. During apnea, the carbon dioxide flow returning to the lungs is significantly reduced to $8-20$ $\mathrm{ml} / \mathrm{min}$ while the oxygen flow to the blood is maintained. Therefore, negative pressure is generated in the lungs according to the volume difference during oxygen and carbon dioxide exchange; this facilitates the movement of oxygen from the pharynx to the lungs $[8,22]$.

Apneic oxygenation could be applied in various clinical situations involving different types of devices, including nasal prongs, nasopharyngeal catheters, and tracheal or bronchial catheters. The first two are commonly used because they are practical [8]. Oxygenation with nasal prongs at $5 \mathrm{l} / \mathrm{min}$ during $\mathrm{FOB}$ intubation could lower the decrease in $\mathrm{PaO}_{2}$ at 3 min during apnea [23]. In Teller's crossover study evaluating the influence of oxygen delivery via a nasopharyngeal catheter at $3 \mathrm{l} /$ min, apnea was continued for 10 min or until $\mathrm{SpO}_{2}$ decreased to $92 \%$. None of the patients in the apneic oxygenation group showed an $\mathrm{SpO} 2$ of $<97 \%$ until $10 \mathrm{~min}$. On the other hand, the mean apnea time in the control group was $6.8 \mathrm{~min}$ and the lowest $\mathrm{SpO}_{2}$ value was $91 \%$ [24]. In present study, we used the working channel of FOB to continuously deliver oxygen as FOB moved toward the trachea. This increases the efficiency of oxygen delivery to the lungs and could be particularly useful for patients prone to desaturation during apnea, such as obese patients [25].

One limitation of apneic oxygenation is that it cannot efficiently remove carbon dioxide from the blood, resulting in an increase in the carbon dioxide level at a rate of $1.1-3.4 \mathrm{mmHg} / \mathrm{min}$ and, eventually, hypercarbia and acidosis [8]. Therefore, it should not be used in patients 
Table 2 Primary and secondary endpoints

\begin{tabular}{|c|c|c|c|}
\hline & No Oxygen $(n=17)$ & Oxygen $(n=18)$ & $P$-value \\
\hline \multicolumn{4}{|l|}{ Heart rate (bpm) } \\
\hline $\mathrm{T} 1$ & $75.1 \pm 15.5$ & $67.9 \pm 10.4$ & 0.291 \\
\hline $\mathrm{T} 2$ & $93.4 \pm 15.9$ & $87.2 \pm 14.9$ & 0.261 \\
\hline \multicolumn{4}{|l|}{$\mathrm{SBP}(\mathrm{mmHg})$} \\
\hline $\mathrm{T} 1$ & $105.2 \pm 21.7$ & $106.1 \pm 17.4$ & 0.428 \\
\hline $\mathrm{T} 2$ & $142.4 \pm 33.1$ & $132.1 \pm 27.5$ & 0.391 \\
\hline \multicolumn{4}{|l|}{$\mathrm{DBP}(\mathrm{mmHg})$} \\
\hline $\mathrm{T} 1$ & $57.8 \pm 12.0$ & $61.9 \pm 14.5$ & 0.437 \\
\hline $\mathrm{T} 2$ & $79.9 \pm 19.6$ & $77.8 \pm 18.1$ & 0.656 \\
\hline \multicolumn{4}{|l|}{$\mathrm{SpO}_{2}(\%)$} \\
\hline T1 & $99.4 \pm 0.7$ & $99.4 \pm 0.9$ & 0.809 \\
\hline $\mathrm{T} 2$ & $99.0 \pm 1.3$ & $98.7 \pm 1.2$ & 0.376 \\
\hline \multicolumn{4}{|l|}{$\mathrm{pH}$} \\
\hline T1 & $7.4 \pm 0.1$ & $7.4 \pm 0.0$ & 0.106 \\
\hline $\mathrm{T} 2$ & $7.3 \pm 0.0$ & $7.3 \pm 0.0$ & 0.373 \\
\hline \multicolumn{4}{|l|}{$\mathrm{SaO}_{2}$} \\
\hline $\mathrm{T} 1$ & $99.9 \pm 0.2$ & $99.9 \pm 0.1$ & 0.929 \\
\hline $\mathrm{T} 2$ & $99.4 \pm 1.2$ & $99.6 \pm 1.4$ & 0.335 \\
\hline \multicolumn{4}{|l|}{$\mathrm{PaCO}_{2}$} \\
\hline T1 & $37.6 \pm 6.4$ & $38.3 \pm 6.1$ & 0.552 \\
\hline $\mathrm{T} 2$ & $46.7 \pm 6.6$ & $47.5 \pm 6.1$ & 0.632 \\
\hline \multicolumn{4}{|l|}{$\mathrm{PaO}_{2}(\mathrm{mmHg})$} \\
\hline $\mathrm{T} 1$ & $415.0 \pm 90.4$ & $379.7 \pm 72.3$ & 0.137 \\
\hline $\mathrm{T} 2$ & $275.6 \pm 94.9$ & $307.8 \pm 97.2$ & 0.322 \\
\hline $\mathrm{PaO}_{2}$ difference $(\mathrm{mmHg})$ & $139.4 \pm 74.3$ & $72.0 \pm 67.7$ & 0.012 \\
\hline Intubation time (sec) & $145.5 \pm 74.8$ & $155.9 \pm 70.1$ & 0.632 \\
\hline $\mathrm{VPaO}_{2}(\mathrm{mmHg} / \mathrm{sec})$ & $1.0 \pm 0.4$ & $0.4 \pm 0.4$ & 0.000 \\
\hline Visual field & & & 0.183 \\
\hline Excellent & 7 & 12 & \\
\hline Good & 8 & 3 & \\
\hline Poor & 2 & 3 & \\
\hline \multicolumn{4}{|l|}{ Complication } \\
\hline PONV (N) & 0 & 1 & 1.000 \\
\hline
\end{tabular}

Values are expressed as mean \pm standard deviation or number

T1, 2 min after manual ventilation with $100 \%$ oxygen, $T 2$ after intubation confirmed with bronchoscopy, before ventilation resumed, SBP systolic blood pressure, $\mathrm{DBP}$ diastolic blood pressure, $\mathrm{SpO}_{2}$ peripheral oxygen saturation, $\mathrm{SaO}_{2}$ arterial oxygen saturation, $\mathrm{PaCO}_{2}$ arterial partial pressure of carbon dioxide, $\mathrm{PaO}$ arterial partial pressure of oxygen, $\mathrm{PaO}_{2}$ difference difference of arterial partial pressure of oxygen between $\mathrm{T} 1$ and $\mathrm{T} 2, \mathrm{VPaO} \mathrm{O}_{2}$ velocity of decrease in arterial partial pressure of oxygen, PONV postoperative nausea and vomiting

with a risk of hypercarbia-related complications. Of late, the use of a high flow nasal cannula has garnered attention in various clinical situations, and it can be effectively used for apneic oxygenation during intubation as well. Studies found that it could deliver a high concentration of oxygen, generate a positive airway pressure of approximately 7 $\mathrm{cmH}_{2} \mathrm{O}$, and slow down the increase in the carbon dioxide level during apneic oxygenation [22, 26]. In the present study, the increase in $\mathrm{PaCO}_{2}$ during the apneic period was similar in the $\mathrm{O}$ and $\mathrm{N}$ groups.

With regard to the visual field, the number of patients with an excellent visual field was not significantly different between groups, although the number was higher in the $\mathrm{O}$ group. This result was inconsistent with those of previous reports, and there are a few possible explanations for the discrepancy. Unlike Rosen's study, which 
included pediatric patients with difficult airways and involved the use of smaller FOBs [5], the present study included adult patients without anticipated difficult airways and involved the use of FOBs with a larger diameter. Moreover, all patients were premedicated with glycopyrrolate in order to minimize secretions [3]. The visual field can be easily disrupted during awake FOB intubation because of patient movement and lens fogginess caused by spontaneous breathing [7]. However, we performed the study under anesthesia with complete muscle relaxation, so there were no disturbances during FOB intubation. Therefore, the intubation conditions were quite good, and the actual effect of oxygen insufflation may not have been as significant as expected.

The two groups in our study showed a comparable intubation success rate and time to intubation; this could be attributed to the lack of differences in the visual field quality. The optimal intubation conditions may be another factor that repressed the influence of oxygen on the intubation-related parameters. We believe that different results may be derived if the measurements were recorded in emergency situations involving patients with unanticipated difficult airways. Further studies should take this aspect into consideration and assess the usefulness of oxygen insufflation during FOB intubation in different clinical scenarios.

From our results, it is evident that oxygen insufflation through the working channel of $\mathrm{FOB}$ can reduce $\mathrm{VPaO}_{2}$ during $F O B$ intubation. Oxygen insufflation through the working channel of FOB can cause rare but serious complications such as gastric rupture and pneumothorax $[10,11,27]$. Oxygen can enter the trachea or esophagus during the procedure. If oxygen is delivered to the esophagus and stomach, it could cause nausea, vomiting $[10,12]$. If $F O B$ with oxygen insufflation enters the stomach, it could cause significant distension of the stomach and even rupture, because the maximal capacity of the stomach is approximately $1 \mathrm{l}$, and FOB could deliver approximately $2.5 \mathrm{l}$ of oxygen in just $30 \mathrm{~s}$, theoretically $[10,28]$. However, according to Wong's review of several studies on nasal or nasopharyngeal apneic oxygenation, no complications related to pressure effects have been reported till date [8]. The esophagus is closed by a sphincter, and approximately $20 \mathrm{~cm} \mathrm{H}_{2} \mathrm{O}$ of pressure is required to open it [29]. According to a previous report using nasal high flow oxygen insufflation, the mean airway pressure was approximately $7 \mathrm{cmH}_{2} \mathrm{O}$ [26], which is considerably lower than the pressure required to open the esophageal sphincter. In the present study, none of the patients complained of vomiting or abdominal distension, and only one patient in group $\mathrm{O}$ developed postoperative nausea. Furthermore, there was no case of mucosal injury or desaturation during the procedure. This was probably due to the optimal intubation conditions and the completion of intubation within 5 min, which is considered safe if the patient is preoxygenated [26].

This study has some limitations. First, FOB intubation was conducted under optimal conditions as described earlier. Therefore, the results cannot be applied to other clinical situations such as emergency difficult airway management. Second, our sample size was enough for $\mathrm{VPaO}_{2}$ measurement but not adequate to assess the occurrence of complications, which are anyways rare.

\section{Conclusions}

In conclusion, our findings suggest that oxygen insufflation through the working channel of FOB can help in extending the apneic window after the induction of general anesthesia during FOB intubation, with minimal complications.

\section{Abbreviations}

FOB intubation: Fiberoptic bronchoscope-assisted intubation; FOB: Fiberoptic bronchoscope; $\mathrm{PaO}_{2}$ : Partial pressure of oxygen; $\mathrm{V}_{\mathrm{PaO} 2}$ : Velocity of decrease in the partial pressure of oxygen; $\mathrm{PaCO}_{2}$ : Partial pressure of carbon dioxide; $\mathrm{SpO}_{2}$ : Peripheral capillary oxygen saturation

\section{Acknowledgements}

Not applicable.

\section{Authors' contributions}

Conceptualization, C.H.C.; Methodology, G.U.R.; Validation, G.U.R. and C.H.C.; Formal Analysis, G.U.R and J.G.K.; Investigation, G.U.R. and C.H.C.; Resources, C.H.C.; Data Curation, C.H.C.; Writing - Original Draft Preparation, G.U.R.; Writing - Review \& Editing, C.H.C., G.U.R. and J.Y.H.; Visualization, G.U.R.; Supervision, C.H.C; Project Administration, J.Y.H. All authors read and approved the final manuscript.

Funding

The authors have nothing to declare.

Availability of data and materials

The datasets used or analysed during the current study are available from the corresponding author on reasonable request.

Ethics approval and consent to participate

This study was approved by the Institutional Review Board of Yonsei University Gangnam Severance Hospital (IRB No 3-2015-0218). After the acquisition of written informed consent, 36 patients aged 20-60 years (American Society of Anesthesiolgists class I to III) who were scheduled for elective surgery under general endotracheal anesthesia with arterial cannulation at Yonsei University Gangnam Severance Hospital were included.

Consent for publication

Not applicable.

\section{Competing interests}

The authors declare that they have no competing interests.

\section{Author details}

'Department of Anesthesiology and Pain Medicine, CHA Bundang Medical Center, CHA University School of Medicine, 59 Yatap-ro, Bundang-gu, Seongnami-si, Gyeonggi-do 13496, Korea. ${ }^{2}$ Department of Anesthesiology and Pain Medicine, and Anesthesia and Pain Research Institute, Yonsei University College of Medicine, Gangnam Severance Hospital, 211 Eonju-ro, Gangnam-gu, Seoul 06273, Korea. 
Received: 28 July 2020 Accepted: 5 November 2020

Published online: 10 November 2020

\section{References}

1. Caplan RA, Posner KL, Ward RJ, Cheney FW. Adverse respiratory events in anesthesia: a closed claims analysis. Anesthesiology. 1990;72(5):828-33.

2. Hove LD, Steinmetz J, Christoffersen JK, Moller A, Nielsen J, Schmidt H. Analysis of deaths related to anesthesia in the period 1996-2004 from closed claims registered by the Danish patient insurance association. Anesthesiology. 2007;106(4):675-80

3. Collins SR, Blank RS. Fiberoptic intubation: an overview and update. Respir Care. 2014;59(6):865-78 discussion 78-80.

4. Xue FS, Cheng Y, Li RP. Awake intubation with video laryngoscope and fiberoptic bronchoscope in difficult airway patients. Anesthesiology. 2013; 118(2):462-3.

5. Rosen DA, Rosen KR, Nahrwold ML. Another use for the suction port on the pediatric flexible bronchoscope. Anesthesiology. 1986;65(1):116.

6. Roberts JT. Preparing to use the flexible fiber-optic laryngoscope. J Clin Anesth. 1991;3(1):64-75.

7. Benumof JL. Management of the difficult adult airway. With special emphasis on awake tracheal intubation. Anesthesiology. 1991;75(6):1087110.

8. Wong DT, Yee AJ, Leong SM, Chung F. The effectiveness of apneic oxygenation during tracheal intubation in various clinical settings: a narrative review. Can J Anaesth. 2017;64(4):416-27.

9. Bennett-Guerrero E, Stolp BW. Fiberoptic intubation. N Engl J Med. 2011 365(6):574 author reply 5-6.

10. Chapman N. Gastric rupture and pneumoperitoneum caused by oxygen insufflation via a fiberoptic bronchoscope. Anesth Analg. 2008;106(5):1592.

11. Khan RM, Sharma PK, Kaul N. Barotrauma: a life-threatening complication of fiberoptic endotracheal intubation in a neonate. Paediatr Anaesth. 2010; 20(8):782-4.

12. Ho CM, Yin IW, Tsou KF, Chow LH, Tsai SK. Gastric rupture after awake fibreoptic intubation in a patient with laryngeal carcinoma. Br J Anaesth. 2005;94(6):856-8.

13. Rosenstock CV, Thogersen B, Afshari A, Christensen AL, Eriksen C, Gatke MR. Awake fiberoptic or awake video laryngoscopic tracheal intubation in patients with anticipated difficult airway management: a randomized clinical trial. Anesthesiology. 2012;116(6):1210-6.

14. Lohse J, Noppens R. Awake video laryngoscopy - an alternative to awake fiberoptic intubation? Anasthesiol Intensivmed Notfallmed Schmerzther. 2016;51(11-12):656-63.

15. Law JA, Morris IR, Brousseau PA, de la Ronde S, Milne AD. The incidence, success rate, and complications of awake tracheal intubation in 1,554 patients over 12 years: an historical cohort study. Can J Anaesth. 2015;62(7): 736-44.

16. Ara T, Mori G, Adachi E, Asai T, Okuda Y. Combined use of the GlideScope and fiberoptic bronchoscope for tracheal intubation in a patient with difficult airway. Masui. 2014;63(6):647-9.

17. Gu J, Xu K, Ning J, Yi B, Lu K. GlideScope-assisted fiberoptic bronchoscope intubation in a patient with severe rheumatoid arthritis. Acta Anaesthesiol Taiwanica. 2014;52(2):85-7.

18. Sharma D, Kim LJ, Ghodke B. Successful airway management with combined use of Glidescope videolaryngoscope and fiberoptic bronchoscope in a patient with Cowden syndrome. Anesthesiology. 2010; 113(1):253-5.

19. Kanda T, Kasai H, Sanefuji Y. Fiberoptic tracheal intubation through the supraglottic airway device air-Q in a patient with Shprintzen-Goldberg syndrome. Masui. 2013:62(8):942-5.

20. Arevalo-Ludena J, Arcas-Bellas JJ, Alvarez-Rementeria R, Alameda LE. Fiberoptic-guided intubation after insertion of the i-gel airway device in spontaneously breathing patients with difficult airway predicted: a prospective observational study. J Clin Anesth. 2016;35:287-92.

21. Moore A, Gregoire-Bertrand F, Massicotte N, Gauthier A, Lallo A, Ruel M, et al. I-gel versus LMA-Fastrach Supraglottic airway for flexible bronchoscope-guided tracheal intubation using a Parker (GlideRite) endotracheal tube: a randomized controlled trial. Anesth Analg. 2015;121(2): 430-6.

22. Patel A, Nouraei SA. Transnasal humidified rapid-insufflation Ventilatory exchange (THRIVE): a physiological method of increasing apnoea time in patients with difficult airways. Anaesthesia. 2015;70(3):323-9.
23. Lee SC. Improvement of gas exchange by apneic oxygenation with nasal prong during fiberoptic intubation in fully relaxed patients. J Korean Med Sci. 1998;13(6):582-6.

24. Teller LE, Alexander CM, Frumin MJ, Gross JB. Pharyngeal insufflation of oxygen prevents arterial desaturation during apnea. Anesthesiology. 1988; 69(6):980-2.

25. Ramachandran SK, Cosnowski A, Shanks A, Turner CR. Apneic oxygenation during prolonged laryngoscopy in obese patients: a randomized, controlled trial of nasal oxygen administration. J Clin Anesth. 2010;22(3):164-8.

26. Ritchie JE, Williams AB, Gerard C, Hockey H. Evaluation of a humidified nasal high-flow oxygen system, using oxygraphy, capnography and measurement of upper airway pressures. Anaesth Intensive Care. 2011;39(6):1103-10.

27. Ovassapian A, Mesnick PS. Oxygen insufflation through the fiberscope to assist intubation is not recommended. Anesthesiology. 1997;87(1):183-4.

28. Geliebter A, Hashim SA. Gastric capacity in normal, obese, and bulimic women. Physiol Behav. 2001;74(4-5):743-6.

29. Lawes EG, Campbell I, Mercer D. Inflation pressure, gastric insufflation and rapid sequence induction. Br J Anaesth. 1987;59(3):315-8 Lawes, E.G.; Campbell, I.; Mercer, D. Inflation pressure, gastric insufflation and rapid sequence induction. British journal of anaesthesia 1987, 59, 315-318.

\section{Publisher's Note}

Springer Nature remains neutral with regard to jurisdictional claims in published maps and institutional affiliations.
Ready to submit your research? Choose BMC and benefit from:

- fast, convenient online submission

- thorough peer review by experienced researchers in your field

- rapid publication on acceptance

- support for research data, including large and complex data types

- gold Open Access which fosters wider collaboration and increased citations

- maximum visibility for your research: over $100 \mathrm{M}$ website views per year

At $\mathrm{BMC}$, research is always in progress.

Learn more biomedcentral.com/submissions 